\title{
EVALUATION OF NATURAL KILLER CELLS USING DIFFERENT TECHNIQUES.
}

\author{
Mohamed A. Selim*¹, Adel A. Mousa ${ }^{2}$, Mohamed T. M. Mansour ${ }^{3}$, Mohamed M.S. Farag ${ }^{4}$. \\ 1,2,4. Department of Botany and Microbiology, Faculty of Science, Al-Azhar University, Nasr \\ City, Cairo, Egypt. \\ 3. Children's Cancer Hospital- 57357 and National Cancer Institute Cairo, Egypt. \\ *Corresponding Author: mohamedselim@azhar.edu.eg
}

\begin{abstract}
Background:

Natural killer (NK) cells mediate spontaneous cytotoxicity toward abnormal and tumor cells and rapidly secrete numerous cytokines and chemokine's which promote subsequent adaptive immune responses. The presented study aimed to compare between different methods for NK evaluation and determination. Ten samples of healthy individuals were collected from Al-Zahraa University hospital and evaluated for phenotypic identification for NK cells. Isolation procedure of NK was performed in Clinical Pathology Department, Hematology Unit, Flowcytometry lab, Al-Azhar University. Protocols started with isolation of peripheral blood mononuclear cells (PBMCs) from fresh human whole blood depending on Ficoll-Paque density gradient centrifugation. Other protocol depended on flow cytometry sorting technique. All experiments were carried out in accordance with the approved guidelines. Sorting procedure using FACS Calibur machine yielded $64.97 \%$ purity before cells were cultured, while mixed Ficoll separation of whole blood showed purity $22.74 \%$. Through our study, it is clear to us that the percentage of purity of NK cells using the flow-cytometry sorting technique is much higher than the percentage of purity of NK cells using the separation method dependent on Ficoll-Paque density technique, Therefore, through our study, we see that it is better to rely on the flowcytometry sorting technique using the flow cytometry device and CD56 +CD16 and CD3 antibodies in order to obtain the best purity of the NK cells (CD56+ CD16 positive /CD3 negative population) for use in medical purposes and laboratory research.
\end{abstract}

Keywords: FACS Calibur, Natural Killers, PBMCS, Ficoll. 


\section{Introduction}

NK cells, first identified in 1975, are innate effector lymphocytes that differ from T cells and B cells. NK cells can recognize and kill abnormal cells that lack MHC restriction or prior sensitization and are considered as the most effective immune cell subpopulation to monitor and clear diseased cells in vivo. NK cells are developed from common lymphoid progenitor cells in the bone marrow (BM) and exist within primary and secondary lymphoid tissue, as well as within non-lymphoid tissue including the lungs, liver, and the peripheral blood (PB) (Weilei Hu et al., 2019).

Human NK cells comprise $10-15 \%$ of circulating lymphocytes, and they are present in both lymphoid organs and nonlymphoid peripheral tissues (Artis \& Spits, 2015; Cooper et al., 2001; Freud $\boldsymbol{e t}$ al., 2017). They are commonly defined as a population of CD3-negative and CD56+positive cells (Spits et al., 2013; Walker, Barlow, \& McKenzie, 2013).NK cells develop outside the thymus in various other tissues, and they do not express a rearranged T-cell receptor (TCR) (Freud et al.,2017).

The NK cells express an array of receptors including inhibitory and activating receptors, inducing negative and positive signals when combined with their ligands, which can determine whether or not NK cells become activated, enabling them to detect infected or neoplastic cells while sparing normal cells (Yamagiwa et al., 2009).

NK cells exert their effects mainly through the recognition and killing of target cells and the secretion of cytokines such as interferon- (IFN $\gamma$ ) and tumor necrosis factor- (TNF- $\alpha$ ), NK cells also play an important role in bridging the innate and adaptive immune responses (Polo $\boldsymbol{e t}$ al., 2019). The balance between activating and inhibitory signals is important in the activation of NK cells. For this, the amounts of ligands expressed on the target cells are crucial, in addition to the amounts of activating and inhibitory receptors expressed on NK cells. Although tumor cells and virus-infected cells with decreased or absent MHC class I molecule expression can escape from attack by cytolytic T-lymphocytes (CTL), MHC class I molecules, encoded by highly conserved genes, are natural ligands for NK cell inhibitory receptors. However, MHC class I molecules are often down-regulated on cancerous or virus-infected cells, delivering insufficient inhibitory signals, thus activating NK cells (Vivier et al., 2012).

As innate immune cells, natural killer (NK) cells are unique and play pivotal functions in cancer immune surveillance. NK cells can eliminate a variety of abnormal or stressed cells without prior sensitization, and even preferentially kill stem-like cells or cancer stem cells (Weilei Hu et al., 2019). Which works by activating the body's own immune system, has become an increasingly important treatment option for cancers. In recent years, successes in antitumor treatments with antibodies and cell-based immunotherapy has become landmark events in the history of tumor treatment (Weilei Hu et al., 2019).

The focus of NK cell immunotherapy has been developing protocols to isolate NK cells from patients' peripheral blood, expand activated NK cells to large numbers, and return them to the patient in the hope of a potent antitumor effect (Selvan and Dowling, 2015). Multiple approaches have been investigated to develop NK cell adoptive cell therapy using various 
isolation and expansion methods. For all protocols, patient's PBMCs must first be isolated through leukapheresis, a density gradient using Ficoll-Paque solution, or another Good Manufacturing Practice- (GMP-)compliant method. Further NK cell isolation can be achieved using magnetic cell sorting (MACS) to separate CD3-CD56+ cells from PBMCs or T cell depletion using anti-CD3 antibody (OKT-3) (Selvan and Dowling, 2015) MACS sorting is a popular method applied in areas concerning immunology, cancer research, neuroscience, and stem cell research. Through this approach, cells are positively or negatively separated, depending on specific antigens present (Guangchuan wang et al.,2017)Different conclusions and several problems have been identified in the purification of murine NK cells as the result of using different commercial kits (Guangchuan wang et al.,2017) For that reason, an extensive comparative study of two different NK cells isolation kits was performed in the present study(Ficoll-Paque density gradient and flow cytometry sorting technique)

Flow cytometry and cell sorting are well-established technologies in clinical diagnostics and biomedical research. Heterogeneous mixtures of cells are placed in suspension and passed single file across one or more laser interrogation points. Light signals emitted from the particles are collected and correlated to entities such as cell morphology, surface and intracellular protein expression, gene expression, and cellular physiology. Based on user-defined parameters, individual cells can then be diverted from the fluid stream and collected into viable, homogeneous fractions at exceptionally high speeds and a purity that approaches $100 \%$. As such, the cell sorter becomes the launching point for numerous downstream studies (Ibrahim and van den Engh , 2007).

Here, we describe the methods for NK cell isolation from peripheral blood with two different techniques and assays for the assessment of NK cell concentration and Purity using flow cytometry.

\section{Materials and Methods}

\section{Ficoll separation technique}

\section{1-1 Sample collection}

The study was conducted in Al-Zahraa University hospital Egypt. Human whole blood (15ml) was collected in from 10 normal, healthy, human donors ranging from 20-35 years old. blood was collected from Al-Zahraa University hospital blood bank, Egypt, in a vacutainer containing Heparin as anti-coagulant (Greiner bio-one, Australia) and processed immediately within 2 hours of collection. All donors signed a written informed agreement for the study. Differentiation of human mononuclear cells into Natural killer cells achieved by using the PBMCS isolation technique. 


\section{1-2 Regarding to cell density}

Protocol started with isolation of peripheral blood mononuclear cells (PBMCs) from fresh human whole blood depending on Ficoll-Paque density gradient centrifugation. In brief, blood samples were diluted in 1x Balanced Salt Solution (Gibco, UK) at 1:1.4 ratio, $35 \mathrm{~mL}$ of diluted cell suspension (blood/PBS mixture) layered over $15 \mathrm{~mL}$ of Ficoll- Hypaque (GE Healthcare, Life Science, Sweden) in a $50 \mathrm{~mL}$ conical tube. For separation of PBMCs from whole blood effectively, Ficoll/diluted blood mix was centrifuged at different speeds for optimization purposes. The diluted peripheral blood centrifuged at $1600 \mathrm{rpm}$ (400xg) for $30 \mathrm{~min}$ at $20^{\circ} \mathrm{C}$, Used a centrifuge with adjustable acceleration and deceleration settings. The rotor brakes were inactivated entirely to effectively prevent mixing of the phases. (Santosh K Panda and Balachandran Ravindran)

\section{1-3 Collection and Purification of PBMNCs.}

After centrifugation, four distinct layers were observed which consisted of plasma, peripheral blood mononuclear cells (PBMCs), ficoll-paque solution and sedimented red blood cells (RBC) with granulocytes. Upper layer that contains the plasma and most of the platelets discarded, the Buffy coat mononuclear cell layer (lymphocytes, monocytes, and thrombocytes) suspended in $5 \mathrm{ml}$ of $1 \mathrm{x}$ BSS buffer, centrifuged at $1800 \mathrm{rpm}$ for 8 minutes. After centrifugation, RBCs lysis was performed to obtain a pure monocyte population. (10X) RBC lysis buffer was prepared by adding 8.3g NH4Cl (Sigma, Germany), 1.0g KHCO3 (Sigma, Germany), 1.8ml of 5\% EDTA (Sigma, Germany) in $1000 \mathrm{ml}$ of sterile water. RBCs lysis was performed once for $3 \mathrm{~min}$. The lysis process was stopped using a 1x BSS buffer and centrifuged at $1800 \mathrm{rpm}$ for 5 min with no brakes. After centrifugation, PBMC washed twice in $5 \mathrm{ml}$ of $1 \mathrm{x}$ buffer. after the first wash, PBMC Centrifuged at $350 \mathrm{xg}(1300 \mathrm{rpm}$ for $8 \mathrm{~min}$ at room temperature while cells centrifuged at low speed $200 \mathrm{xg}$ (1000 rpm for $10 \mathrm{~min}$ for platelet removal. (Santosh K Panda and Balachandran Ravindran)

\section{1-4 PBMNCS Count and Viability}

Finally, the PBMCs white pellet obtained, resuspended immediately in RPMI-10 complete medium (Gibco, United Kingdom) with (10\% fetal bovine-serum (FBS), insulin, penicillin \& streptomycin, glutamic acid and hydrocortisone) for cells counting, purity and viability determination by trypan blue exclusion test. 1x106 PBMCs/mL resuspended, plated in DMEM-10 ml complete medium. (Santosh K Panda and Balachandran Ravindran)

We assessed the prevalence of NK cell through Flow-cytometry (BD, Biosciences, San jose, USA) using CD3 /CD56+CD16 monoclonal Ab.

1. Sorting technique using multi-color FACS Calibur Flow cytometry machine Flowcytometry was conducted in the Clinical Pathology Department, Hematology unit, Flowcytometry lab, Al-Azhar University using multi-color FACS Calibur (BD, Biosciences, San jose, USA). Cell-Quest Pro software (BD Biosciences, San jose, USA) was used for data analysis. Compensation setting was established before acquiring the samples using color calibrate beads (BD, Biosciences, San jose, USA, lot no. 5093879). 


\section{2-1 Sorting Protocol}

\section{2-1-1 Staining protocol:}

Firstly, number of Cells were adjusted to $20-50 \times 10 \% \mathrm{ml}$. Then $100 \mathrm{ul}$ of cells were added to be stained into a conical sterile FACS $5 \mathrm{ml}$ tubes. Fluorescent conjugated monoclonal antibodies which stain the specific clusters of differentiation of NK cells to be sorted were added; we used 20 $\mu 1$ of cocktail of FITC-conjugated anti-human CD3/ PE-conjugated antihuman CD16+CD56 (catalogue no.95131, lot no.6012680 ) from (BD Biosciences, USA) to every tube. Vortex tubes for 10 seconds before incubation in dark for 25 minutes. Then Red blood cells destruction was performed by adding lysis not fixing reagent for 5 minutes using BD lyse reagent, then centrifuged at $1500 \mathrm{rpm}, 37^{\circ} \mathrm{C}$ for 3 minutes. Supernatant removed; Cells harvested in the pellet were washed by FACS staining buffer once. Cells Re-suspended in $300 \mathrm{ul}$ FACS staining buffer. (This buffer was used for all washes until directed to use Sorting Buffer as during sorting cells must be in low protein buffer. Acquisition of tubes to the instrument for NK to be sorted.50 mL sterile conical collection tubes were connected to the sorter machine to collect the sorted cells later after gating on CD56+CD16 Positive and CD3 Negative only. Collection tubes prepared with collection media which is supplemented with fetal bovine serum (FBS) (Andreas Radbruch 1999).

\section{2-1-2 Gating strategy of sorting natural killer isolate}

Initial gating on dot plot graph using forward and sideway scatters (FS/ SS). Gating was specified to lymphocytes expected region (R1) then cells were examined on quadrant plot in which, CD56+CD16 PE were detected on Y axis and CD3 FITC was detected on X axis of the quadrant plot. NKs subsets were defined according to the surface markers expression as CD56+CD16 positive only, while being CD3 negative. According to our strategy NK population was in upper left (UL) quadrant of the plot, referred to by black arrow and named (R2). Corresponding isotype control was used to determine cutoff of positivity (Sorting gate was set as $\mathrm{R} 1$ and R2 on recovery mood. Cells were collected in $50 \mathrm{~mL}$ sterile conical tubes to assessed later for purity (Figure1)
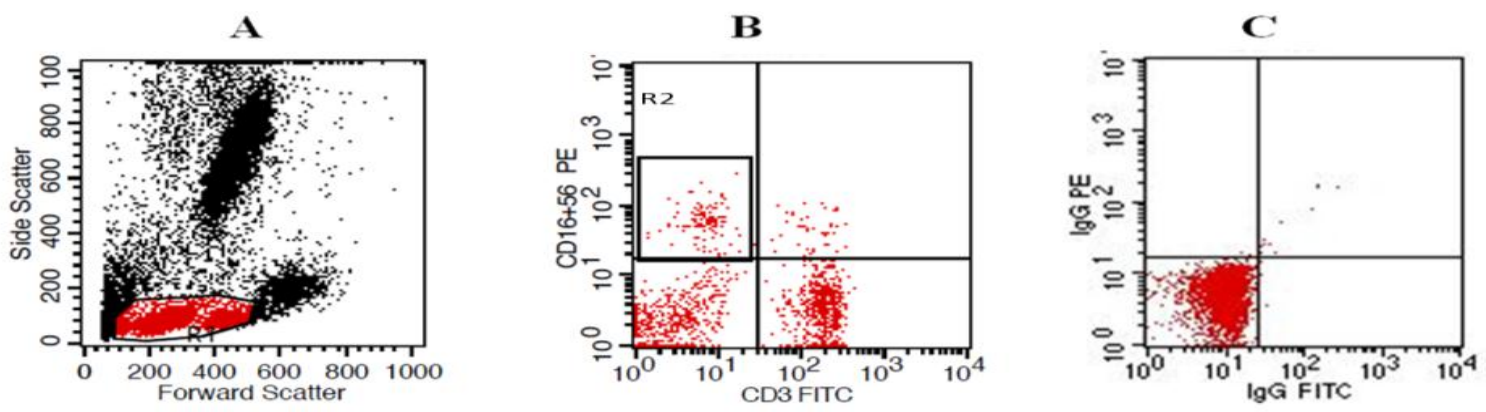

Figure 1: Illustrates gating strategy for NKs sorting [A] Dot plot for initial gating of lymphocyte region on FS/ SS with extending the gating region to include small and large sized lymphocytes (R1); [B] Detection of NKs. NKs were defined as (CD3 FITC negative/CD56+CD16 PE positive) cells residing in (R2). [C] Quadrant plot for isotype control to set cut off positivity. Sorting gate was determined as [R1 AND R2]. 


\section{Results}

- 1-Regarding Ficoll separation technique after we separated PBMCs from $10 \mathrm{ml}$ heparinized fresh blood which include NK cells and other lymphocytes and monocytes. samples reintroduction to flow cytometry devise to assess purity after centrifugation and resuspending in $1 \mathrm{ml}$ PBS Percentage of NK in PMCs mixture ranged 10-25\% (Figure 2

A) when represents CD16+56+ve and CD3-ve (Figure2A).
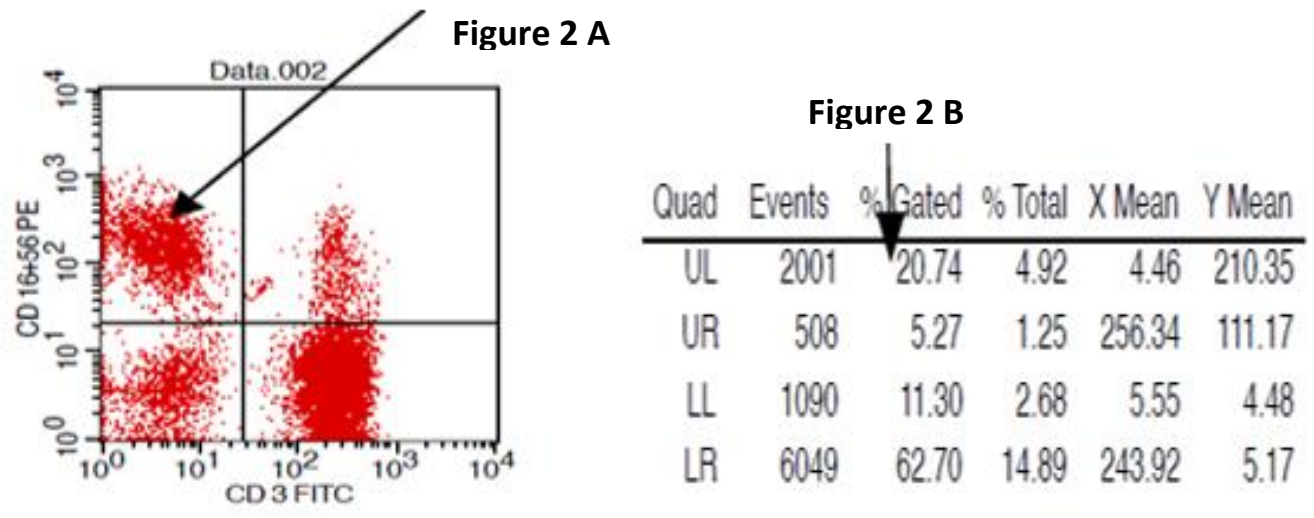

Figure 2: represents natural killer yield post Ficoll separation of mononuclear cells followed by identification using Flowcytometry.CD56+CD16 positive and CD3 negative population is arrowed (different ranges in different samples ranging from 10-25\%.) Figure $2 \mathrm{~A}$.

- 2-Regarding flow-cytometry sorting technique. Stained processed heparinized sorted samples reintroduction to flow cytometry devise to assess purity after centrifugation and resuspending in $1 \mathrm{ml}$ PBS, revealed fixed purity of $64.97 \%$ in NK (CD56+CD16 positive and CD3 negative) in all samples introduced (Figure 3).

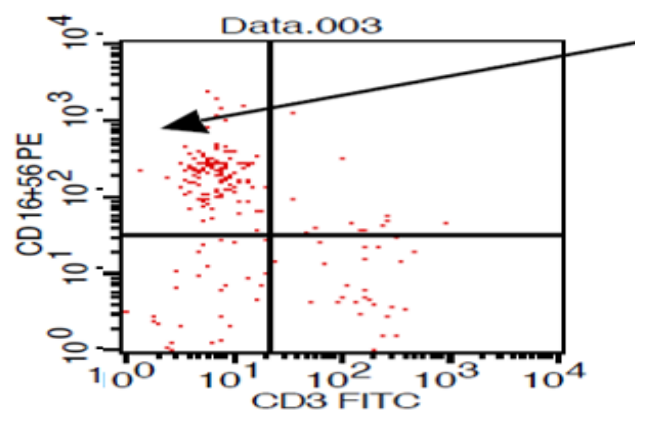

Figure $3 \mathrm{~A}$

Figure 3 B

\begin{tabular}{|c|c|c|c|c|c|}
\hline Quad & Events & Gated & $\%$ Total & $\mathrm{X}$ Mean & Y Mean \\
\hline UL & 128 & 64.97 & 4.44 & 7.37 & 276.90 \\
\hline UR & 13 & 6.60 & 0.45 & 181.90 & 172.95 \\
\hline LL & 30 & 15.23 & 1.04 & 7.57 & 9.91 \\
\hline LR & 26 & 13.20 & 0.90 & 188.65 & 9.64 \\
\hline
\end{tabular}

Figure 3: Post sorting purity testing. Showed that the purity of NK cells which represented at CD56+CD16 positive and CD3- average was $64.97 \%$ at chosen samples.CD56+CD16 positive and CD3 negative population was arrowed in figure $3 \mathrm{~A}$. 


\section{Discussion:}

NK cells are innate lymphocytes that provide host protection against infectious diseases and cancer. In vitro studies of NK cells are necessary to obtain fundamental information on their function and the mechanisms of their interaction with other cells (Guangchuan wang $\boldsymbol{e t}$ al.,2017). A prerequisite for further detailed functional characterization of NK cells is how to optimize the purification method. In previous studies, the purity of NK cells was identified to be varied among the different purification kits used, despite the same method being applied. More granulocytes were detected in the purified NK cells using the Miltenyi sorting kit, particularly while using the negative selection kit (Guangchuan wang $\boldsymbol{e t}$ al.,2017). The main drawback of DX5-positive selection using Stem cell and Miltenyi kits was that a high percentage of CD3 $\varepsilon^{+}$ cells were mixed into the isolated NK cells. Furthermore, a significant difference in NK cell purity was observed while the purification was performed using different surface markers. Therefore, the positive selection kit procedure was modified, and a higher purity and yield of NK cells was obtained. Moreover, the purity of NK cells was compared with the viability with or without a range of concentrations of IL-2. In conclusion, it is important to consider that different NK cell isolation kits affect the purity and yield of isolated NK cells (Guangchuan wang $\boldsymbol{e t}$ al.,2017). When isolating NK cells using Miltenyi kits, the spleen cells should be pretreated to deplete the granulocytes prior to sorting. Combined use of the CD3 $\varepsilon$ selection kit with the DX5 selection kit can produce higher purity and yield of NK cells. Previous studies favor the use of the negative selection kit from Stem cell, which can produce native NK cells that may be further analyzed. In this study, we aim to obtain the best degree of purity for natural killer cells using different methods from the existing methods that depend on magnetic separation of cells (MACS)of both types Positive and negative selection which are very expensive and face some difficulties, with the purpose of using them in the laboratory for advanced research purposes including immunotherapy For many chronic viral diseases, as well as many types of human diseases (Guangchuan wang $\boldsymbol{e t}$ al.,2017). In agreement with (timonen. $t$ and saksela. e 1980) Ficoll-Paque density gradient centrifugation techniques described was easy to perform, did not require expensive equipment and yielded NK cells of satisfactory purity. The presented study aimed to compare between two different methods for NK evaluation and determination. In the present study the purity of NK cells was identified to be varied among the different purification methods used, our study is the first comparative study between Ficoll-Paque density gradient centrifugation technique and flow cytometry sorting technique. So that the present comparative study shed light on two techniques of isolation of NK cells from PBMNCs and the results showed that the Purity of harvested NK were better (46.97\%) in the flow cytometry sorting technique than Ficoll-Paque density gradient centrifugation technique $(22.74 \%)$. Therefore, through our study, we see that it is better to rely on the flow-cytometry sorting technique using the flow cytometry device and CD56+CD16 /CD3 antibodies in order to obtain the best purity of the NK cells( a population of CD56+CD16 positive and CD3 negative) for use in medical and research purposes in the laboratory. 


\section{Conclusion}

The present comparative study shed light on two techniques of isolation of NK cells from PBMNCs and the results showed that the Purity of harvested NK yielded higher and fixed percentage of purity $(64.97 \%)$ in flow cytometry sorting technique while Ficoll-Paque density gradient centrifugation technique was less and ranging in samples with average of $(22.74 \%)$.

\section{REFERENCES:}

Andreas Radbruch. (1999). Flow cytometry and cell sorting 1, ed. - 2nd ed. p. cm. - (Springer lab manual) Includes bibliographical references and index. ISBN 978-3-642-08492-8 DOI 10.1007/978-3-662-04129-1 I. Flow cytometry. I. Radbruch, A. (Andreas) II. Series QH585.5. F56F55 1999.

Artis, D., \& Spits, H. (2015). The biology of innate lymphoid cells. Nature, 517, 293301.Chiesa, S., Mingueneau, M., Fuseri, N., Malissen, B., Raulet, D. H., Malissen, M., et al. (2006). Multiplicity and plasticity of natural killer cell signaling pathways. Blood, 107,2364-2372.

Bertoletti A, Ferrari C.(2012) Innate and adaptive immune responses in chronic hepatitis B virus infections: towards restoration of immune control of viral infection. Gut. 61:175464.

Cooper MA, Colonna M, Yokoyama WM. (2009) Hidden talents of natural killers: NK cells in innate and adaptive immunity. EMBO Rep.; 10:1103-10.

Cooper MA, Fehniger TA, Caligiuri MA. ( 2001) The biology of human natural killer-cell subsets. Trends Immunol.; 22:633-40.

Cooper MA, Fehniger TA, Turner SC, et al. (2001)Human natural killer cells: a unique innate immunoregulatory role for the CD56(bright) subset. Blood.; 97:3146-51.

Doherty DG, Norris S, Madrigal-Estebas L, et al. (1999)The human liver contains multiple populations of NK cells, T cells, and CD3+ CD56+ natural T cells with distinct cytotoxic activities and Th1, Th2, and Th0 cytokine secretion patterns. J Immunol.; 163:2314-21.

Fattovich G, Bortolotti F, Donato F. (2008)Natural history of chronic hepatitis B: special emphasis on disease progression and prognostic factors. J Hepatol.; 48:335-52.

Ferrari C, Missale G, Boni C, Urbani S. (2003)Immunopathogenesis of hepatitis B. J Hepatol.;39 Suppl 1: S36-42.

Freud, A. G., Mundy-Bosse, B. L., Yu, J., \& Caligiuri, M. A. (2017). The broad spectrum of human natural killer cell diversity. Immunity, 47, 820-833. 
GUANGCHUAN WANG, GUANG YU, DONGMEI WANG, SHENGNAN GUO and FENGPING SHAN (2017) Comparison of the purity and vitality of natural killer cells with different isolation kits, EXPERIMENTAL AND THERAPEUTIC MEDICINE 13: 1875-1883,

Guidotti LG, Chisari FV. (2006) Immunobiology and pathogenesis of viral hepatitis. Annu Rev Pathol.; 1:23-61.

Guidotti LG, Rochford R, Chung J, Shapiro M, Purcell R, Chisari FV. (1999) Viral clearance without destruction of infected cells during acute HBV infection. Science.; 284:825-9.

Han Q, Zhang C, Zhang J, Tian Z. (2013) The role of innate immunity in HBV infection. Semin Immunopathology.; 35:23-38.

Huang LR, Wu HL, Chen PJ, Chen DS. (2006) An immunocompetent mouse model for the tolerance of human chronic hepatitis B virus infection. Proc Natl Acad Sci U S A.; 103:17862-7.

Ibrahim SF, van den Engh G. (2007). Flow cytometry and cell sorting book.

Kim JH, Gong CH, Choi GE, Kim SA, Kim HS, Jang YJ (2016). Natural killer cell deficits aggravate allergic rhinosinusitis in a murine model. Otorhinolaryngol Relat Spec. 78:199207.

Lazarova M1, Steinle A1 The NKG2D axis: (2019) an emerging target in cancer immunotherapy. Expert Opin Ther Targets. Apr;23(4):281-294.

Martin MP, Gao X, Lee JH, et al. (2002) Epistatic interaction between KIR3DS1 and HLA-B delays the progression to AIDS. Nat Genet.; 31:429-34.

Medzhitov R, Janeway C Jr. (2000) Innate immunity. N Engl J Med.; 343:338-44.

Orange JS, Fassett MS, Koopman LA, Boyson JE, Strominger JL. (2002) Viral evasion of natural killer cells. Nat Immunol.;3: 1006-12.

Polo ML, Ghiglione YA, Salido JP, Urioste A, Poblete G, Sisto AE, Martinez A, Rolón MJ, Ojeda DS, Cahn PE, Turk GJ, Laufer NL (2019) Liver cirrhosis in HIV/HCVcoinfected individuals is related to NK cell dysfunction and exhaustion, but not to an impaired NK cell modulation by CD4+ T-cells. J Int AIDS Soc. Sep;22(9):

Santosh K Panda and Balachandran Ravindran. (2013), Isolation of Human PBMCs, Vol 3, Iss 3. 
Senthamil R. Selvan1 and John P. Dowling2, (2015) "Adherent", versus Other Isolation Strategies for Expanding Purified, Potent, and Activated Human NK Cells for Cancer Immunotherapy, BioMed Research International Volume |Article ID 869547.

Shao-fei Wua, Wen-jing Wangb, Yue-qiu Gao a, (2015) the Brazilian journal of infectious disease, (Natural killer cells in hepatitis B virus infection braz infectd is;1 9(4):417-425

Thimme R, Wieland S, Steiger C, et al. (2003) CD8(+) T cells mediate viral clearance and disease pathogenesis during acute hepatitis B virus infection. J Virol.; 77:68-76.

TIMONEN. T and SAKSELA. E (1980) ISOLATION OF HUMAN NK CELLS BY DENSITY GRADIENT CENTRIFUGATION. Journal of Immunological Methods, 36, 285--291 285

Vivier E, Tomasello E, Baratin M, Walzer T, Ugolini S. (2008) Functions of natural killer cells. Nat Immunol.; 9:503-10.

Vivier E, Ugolini S, Blaise D, Chabannon C, Brossay L. (2012) Targeting natural killer cells and natural killer T cells in cancer. Nat Rev Immunol.; 12:239-52.

Walker, J. A., Barlow, J. L., \& McKenzie, A. N. (2013). Innate lymphoid cells-How did we miss them? Nature Reviews. Immunology, 13, 75-87.

Weilei Hu, Guosheng Wang, Dongsheng Huang, Meihua Sui and Yibing Xu(2019) Cancer Immunotherapy Based on Natural Killer Cells: Current Progress a New Opportunities, REVIEW published: 31 May 2019 doi10.3389/fimmu.01205.

Wieland S, Thimme R, Purcell RH, Chisari FV. (2004) Genomic analysis of the host response to hepatitis B virus infection. Proc Natl Acad Sci U S A.; 101:6669-74.

Yamagiwa S, Kamimura H, Ichida T. (2009) Natural killer cell receptors and their ligands in liver diseases. Med Mol Morphol.; 42:1-8. 


\section{تقييم الخلايا القاتلة الطبيعية باستخدام تقنيات مختلفة}

$$
\begin{aligned}
& \text { 'محمد عبد الفتاح سليم ` عادل عبد الباسط موسي ‘ محمد طارق منصور *؛حمد منصور سعد فرج } \\
& \text { ؟, ז, قسم النبات و الميكروبيولوجي كلية العلوم بنين جامعة الاز هر القاهرة . }
\end{aligned}
$$

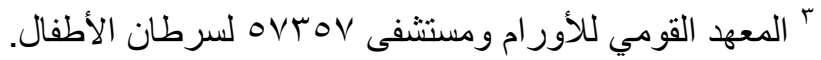

$$
\begin{aligned}
& \text { mohamed.farag@azhar.edu.eg : البريد الاككتروني للباحث الرئيسي }
\end{aligned}
$$

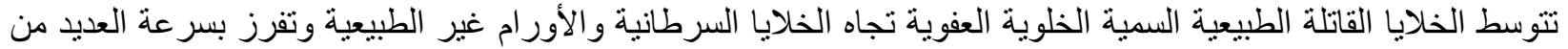

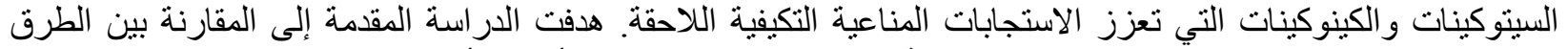

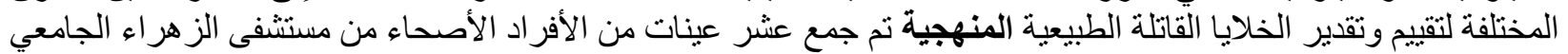

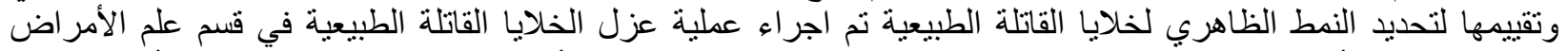

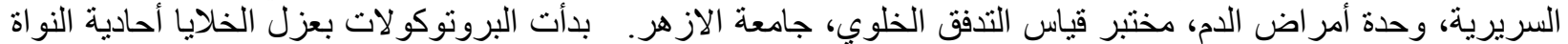

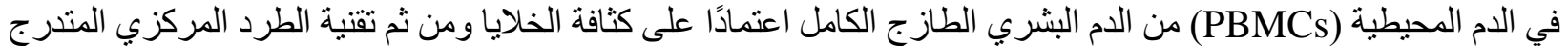

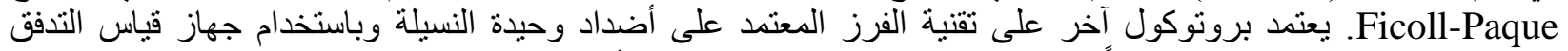

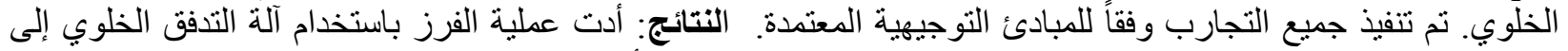

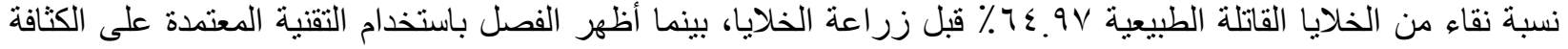

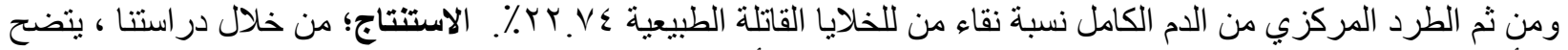

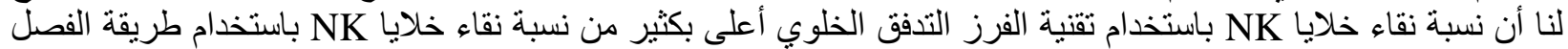

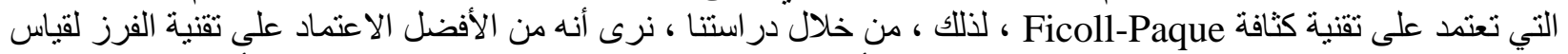

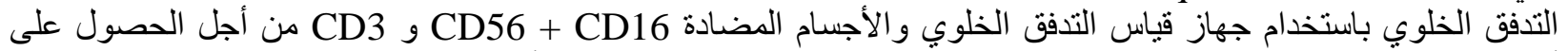
أفضل نقاء لخلايا CD56 + CD16) NK إيجابي / CD3 سلبي) للاستخدام في الأغر اض الطبية والبحوث المختبرية.

الكلمات المفتاحية: الخلايا القاتلة الطبيعية، جهاز التدقق الخلوي، تقنية الكثافة و الطرد المركزي ،الخلايا أحادية النواه 